\title{
Pengembangan Kurikulum Pembelajaran AUD Berbasis Tauhid
}

\author{
Junita Maulidina \\ Email: maulidinajunita@gmail.com \\ Nur Aini \\ Email: Ainicelok88@gmail.com \\ Riskiyanti \\ Email: riskiyanti284@gmail.com \\ Sri Wahyuni \\ Email: Srwhyn2000@gmail.com \\ Institut Agama Islam Negeri Madura
}

\begin{abstract}
This study aims to describe the Development of Tauhid-Based early childhood learning curriculum. This study uses a qualitative appoarch to the type of descriptive research. This data was obtained from through references from jurnals. The result of this study are as follows: 1) the concept monotheism education in early childhood 2) Application of the concept of early childhood monotheism education 3) Monotheism learning planning 4) Implementation of monotheism-based learning. Tauhidbased education is one the solutions for education in Indonesia, Tauhid-based education is the whole educational activity which includes guidance, coacing and development of human potential in accordance with their talents, levels of ability and expertise, which originates and leads to Allah Subhanahu wa Ta'ala. While the basic concept of the Tawheed-based curriculum is implementing an educational curriculum whose content and learning methods lead to the formation of Islamic character to increase devotion to Allah Subhanahu wa Ta'ala.
\end{abstract}

Keywords: Curriculum development, Early Childhood, Tauhid

\begin{abstract}
Abstrak
Penelitian ini bertujuan untuk mendeskripsikan tentang Pengembangan Kurikulum Pembelajaran Anak Usia Dini Berbasis Tauhid. Penelitian ini menggunakan pendekatan kualitatif dengan jenis penelitian deskriptif. Data ini di peroleh dari melalui referensi dari jurnal. Hasil penelitian ini sebagai berikut: 1) Konsep pendidikan Tauhid anak usia dini 2) Penerapan konsep pendidikan anak usia dini 3) Perencanaan pembelajaran tauhid 4) Implementasi pembelajaran berbasis Tauhid. Pendidikan berbasis Tauhid merupakan salah satu solusi untuk Pendidikan di Indonesia, Pendidikan berbasis Tauhid adalah keseluruhan kegiatan Pendidikan yang meliputi pembimbingan, pembinaan dan pengembangan potensi diri manusia sesuai dengan bakat, kadar kemampuan dan keahlian masingmasing yang bersumber dan bemuara kepada Allah Subhanahu wa Ta'ala. Sedangkan konsep dasar dari kurikulum berbasis Tauhid adalah menerapkan sebuah kurikulum Pendidikan yang muatan maupun metode pembelajarannya mengarah kepada pembentukan karakter islami untuk meningkatkan ketaqwaan kepada Allah Subhanahu wa Ta'ala.
\end{abstract}

Kata Kunci: Pengembangan kurikulum, Pembelajaran Anak Usia Dini, Tauhid 


\section{PENDAHULUAN}

Imroatul Hasanah (2015:159) dalam sisdiknas No 20 Tahun 2003 dasar pendidikan anak usia dini adalah Undang-Undang No. 20 tahun 2003 pasal 1 butir 14, berisi tentang pendidikan anak usia dini adalah suatu upaya pembinaan yang ditujukan pada anak sejak lahir sampai usia 6 tahun yang dilakukan melalui pemberian rangsangan pendidikan untuk membantu pertumbuhan dan perkembangan jasmani dan rohani agar anak memiliki kesiapan dalam hal memasuki pendidikan lebih lanjut.

Rozalena \& Muhammad Kristiana (:78-79) sistem pengelolaan pembelajaran PAUD meliputi kegiatan belajar-mengajar, menelaah kalender pendidikan, dan pengaturan jadwal pembelajaran. Dari ketiga hal tersebut saling terkait antara yang satu dengan yang lain dan tidak dapat berdiri sendiri karena akan berpengaruh pada perencanaan, pelaksanaan dan evaluasi pembelajaran di kelas. Pengelolaan pembelajaran di tingkat manapun akan memiliki fungsi untuk memudahkan pengelolaannya dalam mencapai tujuan pendidikan baik secara umum yang tertuang dalam peraturan pemerintah atau undang-undang pendidikan yang berlaku.

Maksudnya dalam melaksanakan pengelolaan pembelajaran diperlukan perencanaan yang baik, pelaksanaan pembelajaran yang sesuai dengan rencana dan pengawasan yang diwujudkan dengan sistem penilaian yang obyektif, jujur, dan menurut standar penilaian yang ditetapkan sebelumnya. Lia Mayasari \& Teguh Tri wilyanto (2013:61) menjelaskan bahwa kurikulum adalah segala pengalaman pendidikan yang diberikan oleh sekolah kepada seluruh anak didiknya baik dilakukan didalam sekolah maupun yang dilakukan di luar sekolah. Ulfa Muadhatin Qaridh, dkk (2018:189) dalam KBBI yang dimaksud dengan kurikulum adalah perangkat mata pelajaran yang diajarkan pada lembaga pendidikan.

Kurikulum merupakan alat untuk mencapai tujuan pendidikan. Istilah kurikulum (curriculum) berasal dari kata curir (pelari) dan curere (tempat berpacu). Pada awlnya istilah kurikulum hanya digunakan dalam dunia olahraga yang diartikan sebagai jarak yang harus ditempuh oleh seorang pelari mulai dari start sampai finish untuk memperoleh medali atau penghargaan. Kemudian pengertian ini diterapkan pada dunia pendidikan menjadi sejumlah mata pelajaran yang harus ditempuh oleh siswa dari awal sampai akhir program pelajaran untuk bisa mendapatkan penghargaan dalam bentuk ijazah. Nur Komariah (79-80)

Hafiedh Hasan (2014:78) mengungkapkan bahwa pendidikan berbasis tauhid merupakan salah satu solusi untuk pendidikan di Indonesia, pendidikan berbasis tauhid adalah keseluruhan kegiatan pendidikan yang meliputi pembimbingan, pembinaan dan pengembangan potensi diri manusia sesuai dengan bakat, kadar kemampuan dan keahlian 
masing-masing yang bersumber dan bermuara kepada Tuhan, Allah Swt. Selanjutnya ilmu dan keahlian yang dimiliki diaplikasikan dalam kehidupan sebagai realisasi pengabdian kepada Allah Swt. Upaya yang dapat dilakukan untuk dapat menempuh jalan itu adalah diawali dari menanamkan nilai-nilai akhlaqul karimah (budi pekerti, tatakrama). Dengan menanamkan akhlaqul karimah sejak usia dini pada anak maka kelak anak akan mengimplementasikan melalui peran kekhalifahan sebagai penmakmur dan pemelihara kehidupan di dunia ini.

Adapun konsep dasar dalam Hafied Hasan (2014:78) dari kurikulum berbasis tauhid adalah menerapkan sebuah kurikulum pendidikan yang muatan maupun metode pembelajarannya mengarah kepada pembentukan karakter islami untuk meningkatkan ketaqwaan kepada Allah Swt. Dan yang lebih prinsip dari kurikulum berbasis tauhid akan selalu mengahdirkan Allah Swt pada semua materi pembelajaran yang dipelajari oleh peserta didik jadi dengan begitu tidak ada pemisahan dan selalu berkaitan antara agama dan kehidupan.

\section{METODOLOGI}

Penelitian ini merupakan penelitian kualitatif yang mendeskripsikan tentang konsep pengembangan kurikulum pembelajaran AUD berbasis tauhid. Metode yang dilakukan disini adalah dengan mengacu kepada banyak sumber referensi dari jurnal. Dengan cara mencari data kemudian mengumpulkan data dan menganalisa data dari sumber informasi.

\section{HASIL DAN PEMBAHASAN}

a. Konsep Pendidikan Tauhid Anak Usia Dini

(Muhammad bin Abdul Wahhab dalam jurnal Ria Astuti dan Erni Munastiwi 2018: 3-4) Tauhid bukan hanya sekedar mengenal ataupun mengerti bahwa pencipta alam semesta ini adalah Allah Swt. Bukan hanya sekedar mengetahui tentang bukti-bukti rasional tentang kebenaran wujud (keberadaan-Nya) dan keesaan-Nya dan bukan pula tentang asma' dan sifat-sifatNya. Namun tauhid yang dimaksud adalah pemurnian ibadah kepada Allah Swt. Artinya menghambakan dirinya pada Allah Swt secara murni dan konsekuen dengan menaati perintah-Nya dan menjauhi larangan-Nya. Dengan penuh rasa rendah diri, cinta, harap dan takut kepadaNya.

Menurut (Fandi Akhmad 2017:32) pendidikan tauhid adalah usaha secara sadar dan terencana untuk mewujudkan suasana belajar dan proses pembelajaran yang bertujuan untuk mengesakan Allah Swt. Allah Swt adalah pencipta, pengatur sehingga 
dengan begitu tidak ada yang berhak disembah kecuali Allah Swt. Dan pada seluruh namnya yang melekat pada Dzatnya.

Pendidikan tauhid adalah suatu upaya yang keras dan bersungguh-sungguh dalam mengembangkan, mengarahkan, membimbing akal, pikiran, jiwa, akal, qalbu dan ruh kepada pengenalan (ma'rifat) dan cinta (mahabbah) kepada Allah Swt. (Lukluk Sismiati 2012:5).

Hakekat dan inti tauhid adalah agar manusia memandang bahwa semua perkara berasal dari Allah Swt. Dan dengan adanya pandangan ini maka membuatnya tidak menoleh pada selain Allah Swt tanpa sebab atau perantara. Konsep tauhid yang diajarkan pada anak usia dini pada umumnya merupakan pemahaman yang menunjukkan bahwa Allah Swt hanya satu dan merupakan Tuhan Yang Maha Esa. Sehingga pembelajaran tauhid di PAUD adalah pembiasaan-pembiasaan ibadah yang dapat mendekatkan anak kepada Allah Swt.

Adapun yang dapat dipelajari anak tentang ketauhidan adalah pemahaman tentang islam, pembiasaan sholat, hafalan doa harian, hafalan surah pendek, hafalan hadits dan kegiatan agama islam. (Ria Astuti \& Erni Munastiwi 2018: 4).

b. Perencanaan pembelajaran Tauhid

Sesuai dengan tahapan perencana pembelajaran yang di jabarkan pada Permendiknas Nomor 58 Tahun 2009 bahwa tahap perencana pembelajaran meliputi perencanaan semester, rencana kegiatan mingguan (RKM) dan rencana kegiatan harian (RKH). Perencanaan pembelajaran pada program semester telah tertuang secara rinci indikator-indikator pembelajaran yang hendak dicapai. Selanjutnya, indicator- indicator tersebut di turunkan pada RKM, dan akan diturunkan lagi pada RKH untuk mencapai tema goals.

Rencana pelaksanaan pembelajaran harus di buat setiap kali akan melakukan pembelajaran. Tanpa adanya perencanaan, pembelajaran akan berjalan tidak terarah dam akan meluas kemana-mana sehingga sulit dipahami oleh anak dan akhirnya tujuan pembelajaran pun tidak dapat tercapai dengan baik. Pada pembelajaran perencaan tauhid ada 3 nilai dalam beriman kepada Allah yang diterapkan yaitu beriman kepada Asma dan sifat Allah, beriman kepada Rububiyah Allah dan beriman kepada huluhiyah Allah. Nilai-nilai ini direncanakan dalam program semester TK yang diulas secara terperinci pada indicator dalam aspek Tauhid dan aspek pembiasaan 
Tauhid. Perkembangan nilai agama dan moral anak erat hubungannya dengan pembentukan karakter anak. Karakter-karakter tersebut termasuk dalam Sembilan pilar karakter dasar yang tertanam pada anak melalui pendidikan sekolah di Indonesia sebagai berikut:

a) Cinta kepada Allah dan semesta beserta isinya,

b) Tanggung jawab, disiplin, dan mandiri,

c) Jujur,

d) Hormat dan santun,

e) Kasih sayang, peduli dan kerja sama,

f) Percaya diri, kreatif, kerja keras dan pantang menyerah,

g) Keadilan dan kepemimpinan,

h) Baik dan rendah hati,

i) Toleransi, cinta damai dan kesatuan.

Sehingga dapat dikatakan bahwa pembelajaran Tauhid yang diterapkan merupakan pembelajaran yang menanamkan pendidikan karakter. Karakter yang dibangun merupan Sembilan pilar karakter yang telah ditanamkan pada anak melalui pendidikan. Karakter pertama yang hendak dibangun pada anak adalah ketaatan kepada Allah SWT dan mejadikan anak untuk meneladani Rasulullah SAW. Oleh karenanya, pendidikan karakter harus dilaksanakan berdasarkan nilai-nilai ajaran Agama. Pendidikan karakter tidak boleh bertentangan dengan Agama.

Dengan demikian Agama merupakan landasan yang pertama dan utama dalam mengembangkan pendidikan karakter di indonesia, khusunya pada lembaga PAUD (Vera Sholeha, 2015: 5-6). Perencanaan kurikulum berbasis Tauhid menurut Lia Mayasari \& Teguh Tri Wilyanto (2003:64) perencanaan kurikulum ini berfungsi sebagai pedoman atau alat manejemen yang berisi petunjuk tentang jenis dan sumber individu yang diperlukan, media pembelajaran yang digunakan, tindakan-tindakan yang dilakukan, sumber biaya, tenaga, dan saran yang diperlukan system monitoring dan evaluasi, peran unsur-unsur ketenagaan untuk mencapai tujuan menejemen Lembaga Pendidikan.

C. Implementasi pembelajaran berbasis Tauhid

Pembelajaran tauhid di PAUD dapat diterapkan sejak anak usia 6 bulan sampai 6 tahun. Sebelum menerapkan pembelajaran Tauhid di kelas, maka diperlukan 
beberapa persiapan yang di lakukan oleh masing-masing guru di kelas. Biasanya persiapan tersebut mereka buat dalam rencana pelaksanaan pembelajaran hariann (RPPH). Pembelajaran yang lebih diutamakan di PAUD adalah pembelajaran Tauhid dan bahasa karena PAUD ini memang berbasis tauhid. Setiap guru di paud sudah mengetahui kewajiban masing-masing dalam proses pembelajaran.

Salah satu kewajiban guru adalah menyediakan media pembelajaran dalam proses mengajar mengajar di kelas agar pembelajaran tersebut menjadi aktif, efektif, kreatif dan menyenangkan. Seorang guru sebelum mengajar harus mempersiapkan materi sesuai pada pembelajaran hari ini apabila membutuhkan lagu maka mereka harus mencari lirik dan music yang dapat membuat anak antusias dan mudah menerima pembelajaran. Guru paud yang baik harus memiliki sikap aktif dan kreatif dalam menyajikan pembelajaran yang menyenangkan selain itu, guru harus paham materi yang akan di berikan pada anak didik sebelum menyampaikannya di dalam kelas.

Sebelum memulai kegiatan belajar mengajar di kelas, maka di mulai dengan membaca doa-doa harian. Surah-surah pendek, dan hadist-hadist pendek. Selain itu anak-anak didik juga di ajak menyanyikan lagu Asmaul-Husna dan 20 sifat wajib Allah. Setelah membaca doa-doa harian, surah-surah pendek dan hadist-hadist pendek anak didik melakukan solat duha yang di mulai dengan ber wudhu', anak-anak belajar melakukan tepuk wudhu' yang di ikuti dengan nyanyian cara berwudhu' yang disertai dengan beberapa kosa kata bahasa inggris.

Setiap hari anak-anak dibiasakan mengaji dengan media buku iqra' atau flash card yang berisi huruf-huruf hijaiyah. Setelah itu anak diajak makan yang disertai dengan doa sebelum dan sesudah makan. Adapun sebelum berdoa di mulai dengan bahasa inggris dan doa tersebut menggunakan tiga bahasa, yakni bahasa arab, bahasa inggris, dan bahasa indonesia. Ketika anak-anak didik pulang juga di biasakan membaca doa-doa dan surah-surah pendek terlebih dahulu. Guru dalam menerapkan pembelajaran tauhid memiliki SOP (standar operasional pembelajaran) yang sudah mengatur dari awal mereka masuk dalam lingkungan sekolah sampai mereka keluar. Bahkan lagu-lagu atau nyanyian yang di berikan pada anak didik harus memiliki nilai nilai pendidikan dan mampu mengembangkan berbagai aspek perkembangan (Ria Astuti \& Erni Munastiwi 2018: 5)

Pelaksaan proses pembelajaran salah satu penentu keberhasilan sistem program pembelajaran yang di terapkan oleh sekolah karena dalam hal ini melibatkan interaksi peserta didik dan guru secara langsung untuk mencapai tujuan pembelajaran. 
Sehingga implikasi dari konsep pendidikan berbasis tauhid dan diterapkan oleh sekolah dan lembaga adalah pada kebijakan dan sistem pembelajaran peserta didik.

Sehingga seluruh kegiatan dan pelaksanaan pembelajaran diarahkan pada konsep tauhid dimana melakukan apa yang diperintahkan dan menjauhi apa yang dilarang oleh Allah. Pada bagian penutup pendidik tetap memberikan motivasi, semnagat kepada peserta didik baik tentang adab, akhlak, maupun perilaku peserta didik denan muatan tauhid. Selain itu dalam kegiatan pembelajaran, peserta didik juga senantiasa di tekankan penanaman adab. Adab merupakan salah satu cara membentuk karakter peserta didik dimana nantinya peserta didik akan memiliki pribadi dan akhlak yang baik dalam kehidupan sehari-hari.

Penanaman adab dan pembiasaan yang dilakukan dalam membenatuk karakter peserta didik diterapkan dalam pembelajaran dan seluruh aktifitas peserta didik, baik pada saat proses belajar mengajar dengan menginternalisasikan muatan tauhid dan adab (Ulfa Muadhatin Qoriah, dkk, 2018: 193-194).

\section{SIMPULAN}

Jadi dapat disimpulkan bahwa pengembangan kurikulum berbasis Tauhid adalah menerapkan sebuah kurikulum Pendidikan yang muatan maupun metode pembelajarannya mengarah kepada pembentukan karakter islami untuk meningkatkan ketaqwaan kepada Allah Subhanahu wa Ta'ala. Serta membiasakan anak-anak untuk selalu istiqomah dalam pembelajaran Tauhid.

Pendidikan Tauhid adalah suatu upaya yang keras dan bersungguh-sungguh dalam mengembangkan, mengarahkan, menggunakan pikiran, jiwa, akal, kalbu dan ruh kepada pengenalan dan cinta kepada Allah Subhanahu wa Ta'ala. Sehingga pembelajaran Tauhid di PAUD adalah pembiasaan-pembiasaan ibadah yang dapat mendekatkan anak kepada Allah Subhanahu wa Ta'ala. Pembelajaran Tauhid di PAUD dapat diterapkan sejak anak usia 6 bulan sampai 6 tahun. Sebelum menerapkan pembelajaran Tauhid di kelas, maka diperlukan beberapa persiapan yang dilakukan oleh masing-masing guru di kelas.

Rencana pelaksanaan pembelajaran harus dibuat setiap kali akan melakukan pembelajaran. Tanpa adanya perencanaan, pembelajaran akan berjalan tidak terarah dan akan meluas kemana-mana sehingga sulit dipahami oleh anak dan akhirnya tujuan pembelajaran pun tidak dapat tercapai dengan baik. Pembelajaran Tauhid di PAUD dapat diterapkan sejak anak usia 6 bulan sampai 6 tahun. Sebelum menerapkan pembelajaran Tauhid di kelas, maka diperlukan beberapa persiapan yang dilakukan oleh masing-masing guru di kelas. 
Pelaksaan proses pembelajaran salah satu penentu keberhasilan sistem program pembelajaran. Implikasi dari konsep pendidikan berbasis tauhid dan diterapkan oleh sekolah dan lembaga adalah pada kebijakan dan sistem pembelajaran peserta didik. Seluruh kegiatan dan pelaksanaan pembelajaran diarahkan pada konsep tauhid dimana melakukan apa yang diperintahkan dan menjauhi apa yang dilarang oleh Allah.

\section{DAFTAR PUSTAKA}

Akhmad Fandi, Pendidikan Tauhid Pada Anak Usia Dini di Taman KanakKanak Al-Qur'an (TPQ) Al-Mukhlisiin Sugih Waras Kecamatan Pemalang Kabupaten Pemalang. 2017. Repository.Iainpurwokerto.ac.id

Astuti, Ria \& Erni Munastiwi. Pendidikan Anak Usia DiniBerbasis Tauhid (Studi Kasus PAUD Ababil Kota Pangkal Pinang). 1 (2) 2018

Hasan, Hafied. Sistem Pendidikan Nasional Berbasis Tauhid. Madaniyah, 4 (1) 2014.

Hasanah, Imroatul, Kurikulum Pendidikan Anak Usia Dini. Konstruktivisme: Jurnal Pendidikan \& Pembelajaran 7 (2) 2015.

Komariah, Nur. Kurikulum Berbasis Al-Qur'an KBQ Pada Anak Usia Dini. Ejournal.fiaunisi.ac.id

Mayasari, Liya \& Teguh Triwiyanto. Manajemen Kurikulum Berbasis Tauhid. 24 (1) 2013.

Qoriah, Ulfa Muadhatin, dkk. Manajemen Implementasi Kurikulum Pembelajaran Berbasis Tauhid dalam Pembentukan Karakter Peserta Didik. JAMP: Jurnal administrasi dan manajemen pendidikan 1(2) 2018.

Rozanelna \& Muhammad Kristiawan, Pengelolaan Pembelajaran PAUD dalam Mengembangkan Potensi Anak Usia Dini. JMKSP: Jurnal manajemen, kepemimpinan dan supervise pendidikan 2 (1) 2017.

Sholeha, Vera. Pelaksanaan Pembelajaran Tauhid di TK Khalifah Wibrobajan. Pendidikan Guru PAUD S-1 2015-journal.student.uny.ac.id

Sismiati, Lukluk. Implementasi Pendidikan Tauhid Usia Dini di Tkit Al Mukmin Ngruki Waringinrejo Cemani Grogol Sukoharjo Tahun Pelajaran 2011/2012. 2012.-eprints.ums.ac.id 